\title{
Sensitized lymphocytes in muscular dystrophy: evidence for a neural factor in pathogenesis
}

\author{
E. A. CASPARY, S. CURRIE, AND E. J. FIELD \\ From the Medical Research Council Demyelinating Diseases Unit, Newcastle General Hospital, \\ Newcastle upon Tyne
}

SUMMARY Lymphocytes of patients suffering from Duchenne and other types of muscular dystrophy and the Kugelberg-Welander syndrome showed marked sensitization to muscle and also to central and peripheral nervous antigens even in preclinical disease. These findings are discussed in relation to the pathogenesis of the disease.

Muscular dystrophy is an inherited disorder in which progressive degeneration of skeletal muscle occurs. This is generally considered to be due to some primary biochemical genetically determined defect in muscle fibres themselves.

The motor innervation of dystrophic muscle has been the subject of much recent work including that of McComas and colleagues (McComas, Sica, and Currie, 1970; Campbell, McComas, and Sica, 1970; McComas and Sica, 1970). They claim that there is electrophysiological evidence of partial denervation of dystrophic muscle even in the earliest stages of clinical disorder when disability is minimal. Using an electrophoretic method (Field and Caspary, 1971; Field, Caspary, Hall, and Clark, 1970) we have looked for evidence of lymphocyte sensitization to antigens of muscular, central and peripheral nervous system origin in patients with various types of muscular dystrophy.

\section{METHODS}

Of 22 patients whose lymphocytes were studied, 10 had Duchenne dystrophy, two of these (aged 1.6 and 2.2 years) being in the preclinical phase; in three others it was moderately advanced, while the remaining five were confined to wheelchairs. Five of the patients were among the 13 with Duchenne dystrophy in whom McComas et al. (1970) had carried out neurophysiological studies. There were two patients with limb girdle dystrophy; three of these had been studied by McComas and colleagues (Campbell et al., 1970; McComas et al., 1970; McComas and Sica, 1970). Seven patients were suffering from relatively benign pseudomyopathic spinal muscular atrophy (the Kugelberg-Welander syndrome). These patients were disabled to some degree, but all remained ambulant. In all 22 patients there was clinical evidence of the selective muscular atrophy which is characteristic of the various conditions included. In all muscle biopsy, neurophysiological studies and serum creatine-kinase estimations had been carried out, so that the diagnosis in each case was as firm as clinical assessment and investigation allowed. Thirtyfour normal subjects have been studied; two being male children aged 2.0 and 2.6 years. These controls were of both sexes but were not matched precisely for age with the dystrophic patients. In addition six hospital patients suffering from unrelated conditions have been examined.

Lymphocyte sensitization was studied by the method previously described (Field and Caspary, 1971; Field, Caspary, Hall, and Clark, 1970) on a suspension obtained from venous blood by defibrination with glass beads and removal of polymorphs with saccharated iron. The antigens used in the present study were encephalitogenic factor (EF) (Caspary and Field, 1965) (a histone-like basic protein made from human brain); human sciatic nerve basic protein (SNBP) (capable of producing allergic neuritis in guinea-pigs when inoculated together with Freund's adjuvant); and, thirdly, a saline extract of human erector spinae muscle obtained at operation.

PROCEDURE $10^{7}$ normal guinea-pig peritoneal macrophages in $1.0 \mathrm{ml}$. of medium 199 were added to $0.5 \times 10^{6}$ of the human lymphocytes to be tested in $0 \cdot 1 \mathrm{ml}$. of medium 199. A further $1.5 \mathrm{ml}$. of the same medium brought the total volume to $3.0 \mathrm{ml}$.- a convenient one for the cytopherometer used. Migration time of the macrophages in this mixture-that is, without addition of antigen-was measured as 'control' time.

Antigens used were encephalitogenic factor-EF, a basic histone-like protein capable of producing experimental allergic encephalomyelitis in guinea pigs in $1 \mu \mathrm{g}$ doses (with Freund's adjuvant); sciatic nerve basic protein-SNBP, capable of producing allergic neuritis; and an aqueous extract of human erector spinae muscle (obtained at operation). Antigen to be tested was added to the control mixture ( $33 \mu \mathrm{g}$ in $1.0 \mathrm{ml}$.) and the migration time of macrophages estimated. This was done in a Zeiss cytopherometer under phase contrast so that macrophages could readily be distinguished by their size and content of liquid paraffin droplets. All specimens were 'coded' 
and studied blind to eliminate observer bias. In each case 10 macrophages were studied in both directions of the potential difference $(180 \mathrm{~V}: 7.5 \mu \mathrm{A})$ so that a mean of 20 readings could be assigned to each specimen.

The time increase for migration over a fixed distance in the cytopherometer field of view was expressed as a percentage of the 'control time'- that is, when no antigen was present. Some difficulties in the method have been discussed elsewhere.

The method depends upon the interaction of blood lymphocytes with antigen to which they are specifically sensitized. As a result some substance is liberated (dependent upon protein synthesis by the lymphocytesCaspary, unpublished) which causes slowing of migration of normal guinea-pig macrophages in an electrophoretic field. Normal guinea-pig macrophages are thus used as a non-specific marker for estimating the effects of interaction of sensitized lymphocytes and antigen. However, some $10-15 \%$ of lymphocytes are present in the normal guinea-pig peritoneal exudate and direct experiment showed that when guinea-pig exudate was mixed with human lymphocytes, macrophage slowing took place on account of a 'mixed lymphocyte' reaction. In order to eliminate this, various fractionation procedures were attempted (Knowles and Hughes, 1970), but finally it was found that reactivity of the guinea-pig lymphocytes (with retention of the macrophage response) could be achieved by exposing the exudate to 100 rads of $x$ irradiation and this has been adopted as a standard procedure.

\section{RESULTS}

From the results set out in Tables 1,2 and 3 it is apparent that all patients suffering from the varieties of muscular dystrophy examined showed wellmarked lymphocyte sensitization to muscle, to cen-

TABLE 1

PATIENTS WITH MUSCULAR DYSTROPHY*

\begin{tabular}{|c|c|c|c|c|c|c|}
\hline No. & $\begin{array}{l}\text { Age } \\
\text { (yr) }\end{array}$ & Sex & E.F. & B.P. & Muscle & Diagnosis \\
\hline 1 & $1 \cdot 8$ & $\mathbf{M}$ & $9 \cdot 3$ & $9 \cdot 7$ & $24 \cdot 4$ & $\begin{array}{l}\text { Pre-clinical } \\
\text { Duchenne }\end{array}$ \\
\hline 2 & 2.5 & $\mathbf{M}$ & $12 \cdot 3$ & $13 \cdot 6$ & $25 \cdot 7$ & $\begin{array}{l}\text { Pre-clinical } \\
\text { Duchenne }\end{array}$ \\
\hline 3 & 6 & $\mathbf{M}$ & 18.4 & 19.9 & $27 \cdot 2$ & Duchenne \\
\hline 4 & 9 & $\mathbf{M}$ & $17 \cdot 0$ & $17 \cdot 3$ & $25 \cdot 8$ & Duchenne \\
\hline 5 & 9 & $\mathbf{M}$ & 15.7 & $13 \cdot 2$ & 21.9 & Duchenne \\
\hline 6 & 12 & $\mathbf{F}$ & $14 \cdot 7$ & 14.9 & $21 \cdot 4$ & Limb girdle \\
\hline 7 & 13 & $\mathbf{M}$ & 19.5 & $15 \cdot 8$ & $23 \cdot 6$ & Duchenne \\
\hline 8 & 14 & $\mathbf{M}$ & $19 \cdot 0$ & 15.0 & $23 \cdot 4$ & Duchenne \\
\hline 9 & 14 & $\mathbf{M}$ & 18.5 & 15.2 & $23 \cdot 0$ & Duchenne \\
\hline 10 & 14 & $\mathbf{M}$ & $13 \cdot 5$ & $15 \cdot 6$ & $23 \cdot 4$ & Duchenne \\
\hline 11 & 15 & $\mathbf{M}$ & 15.5 & $14 \cdot 6$ & $18 \cdot 3$ & Duchenne \\
\hline 12 & 36 & $\mathbf{M}$ & $13 \cdot 8$ & $15 \cdot 4$ & $24 \cdot 0$ & $\begin{array}{l}\text { Facio-humero- } \\
\text { scapular }\end{array}$ \\
\hline 13 & 55 & $\mathbf{F}$ & $16 \cdot 2$ & $23 \cdot 1$ & $17 \cdot 5$ & Limb girdle \\
\hline 14 & 57 & $\mathbf{M}$ & 15.8 & $25 \cdot 3$ & $18 \cdot 1$ & $\begin{array}{l}\text { Myotonic } \\
\text { dystrophy }\end{array}$ \\
\hline 15 & 57 & $\mathbf{M}$ & $16 \cdot 3$ & $13 \cdot 3$ & $22 \cdot 2$ & $\begin{array}{l}\text { Facio-humero- } \\
\text { scapular }\end{array}$ \\
\hline
\end{tabular}

* The figures represent the percentage increase in migration time in the presence of antigen as compared with no antigen at all.
TABLE 2

PATIENTS WITH KUUGELBERG WELANDER DISEASE

\begin{tabular}{lccrccc}
\hline No. & $\begin{array}{c}\text { Age } \\
(y r)\end{array}$ & Sex & E.F. & B.P. & Muscle & Diagnosis \\
\hline 1 & 14 & M & 20.1 & 20.3 & 22.4 & Kugelberg Welander \\
2 & 19 & M & 14.1 & 15.3 & 11.7 & Kugelberg Welander \\
3 & 22 & F & 16.6 & 15.0 & 23.9 & Kugelberg Welander \\
4 & 29 & F & 26.5 & 16.2 & 26.7 & Kugelberg Welander \\
5 & 33 & M & 18.0 & 19.9 & 15.6 & Kugelberg Welander \\
6 & 38 & M & 13.2 & 17.3 & 21.5 & Kugelberg Welander \\
7 & 41 & F & 8.8 & 13.8 & 20.5 & Kugelberg Welander \\
\hline
\end{tabular}

TABLE 3

NORMAL CONTROL SƯBJECTS

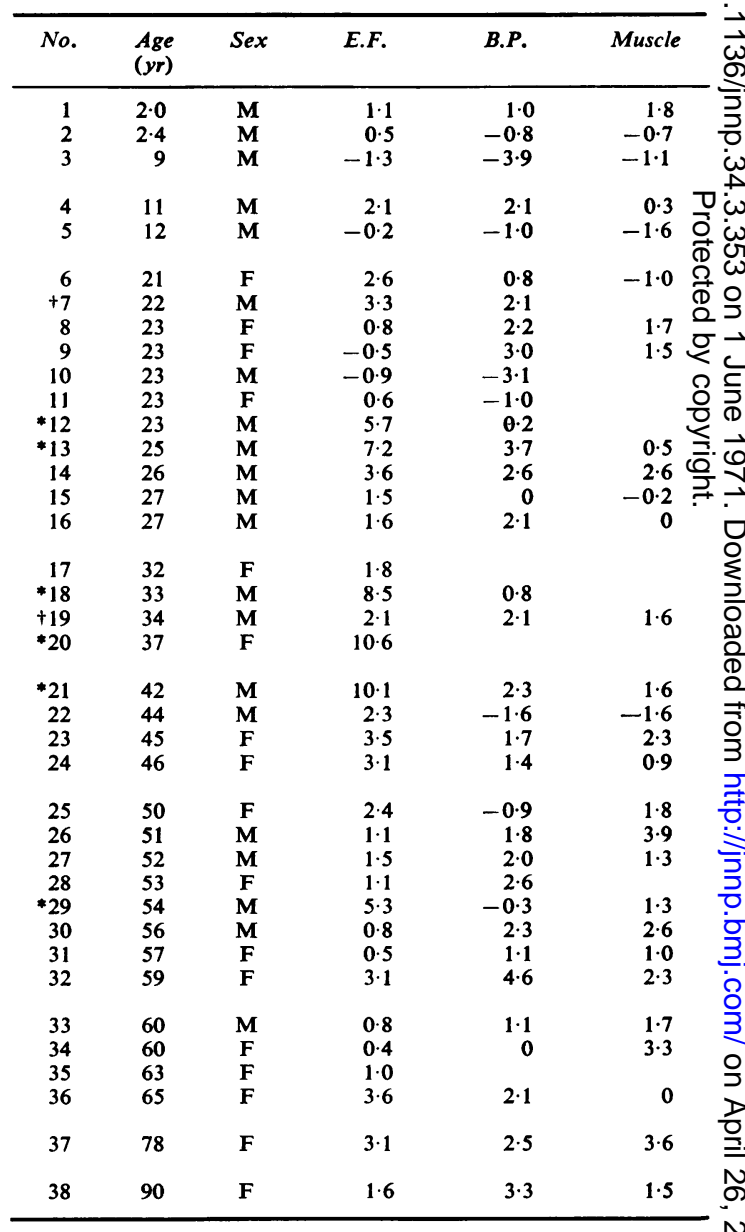

* Laboratory worker working with brain or EF, sometimes mixed with Freund's adjuvant.

tLaboratory worker not working with the above. 
tral nervous system protein (encephalitogenic factorEF), and to sciatic nerve basic protein (SNBP). In two cases additional experiments were done with antilymphocytic serum (ALS). It was found that this could block the positive result with these antigens if introduced into the in vitro system before antigen but not if the antigen had already had an opportunity of reacting with the lymphocytes. This was a further indication that a true immunological interaction of lymphocyte and antigen was taking place (Field et al., 1970).

It can be concluded that every case of muscular dystrophy syndrome examined showed lymphocytes sensitized to muscle; and this was as true for the two 'preclinical' cases as for the rest. In addition all had lymphocytes sensitized to encephalitogenic factor (EF). Sensitization was least in the child aged 20 months suffering from preclinical dystrophy of the Duchenne type $(E F=9.3 \% ;$ SNBP $=9.7 \%)$. This level is well outside the range of normal values except for subjects nos. 12, 13, 18, 20, 21, 29. These comprise a group of workers in this laboratory who handle a good deal of brain - often with Freund's adjuvant-and the high values in their case might well be due to minimal immunization. It is to be noted that low levels were found in the two normal children of age comparable with the preclinical dystrophies.

\section{DISCUSSION}

Sensitization to muscle was not unexpected in the cases of established dystrophy, and to nerve antigens in Kugelberg-Welander cases which are of accepted neurogenic origin. What was not expected was the occurrence of well-marked sensitization to neural antigens in classical cases of muscular dystrophy in which there was no clinical suspicion of peripheral or central neuropathy. The findings may thus reflect possible degeneration in both muscle fibres and motor neurones with secondary sensitization. In the two cases of preclinical muscular dystrophy available for study, sensitization was certainly much more clearly established than to neural antigens and this may be taken to suggest that muscular degeneration was primary and more advanced at this stage. The findings as a whole are certainly compatible with a neurogenic factor in the pathogenesis of dystrophy as suggested by McComas et al. (1970). On the other hand it is conceivable that 'disuse atrophy' of the neural component of the motoneurone unit is consequent upon a primary muscle defect which leads quickly to degenerative changes. These changes would lead to breakdown products to which lymphocytic sensitization takes place. It seems clear that in clinical cases of Duchenne dystrophy there is neural tissue breakdown which has in the past been ignored because attention has been undividedly directed to the muscles. The electrophoretic method employed appears to be a very sensitive measure of lymphocyte sensitization, so that minor degrees can be picked up at an early stage of the process.

It is of interest that lymphocytes from patients in the acute stage of Guillain-Barré syndrome, when muscle wasting was progressing, showed a response to muscle antigen less than to protein of central or peripheral nervous origin (Caspary, Currie, Walton, and Field, 1971). In preclinical dystrophy the reverse situation may hold, though new cases will have to be examined as they become available. By the time the disease becomes clinically well established sensitization to neural antigens appears to be well marked.

The cytopherometric method used in the present work is much more sensitive than lymphocyte transformation in demonstrating sensitized lymphocytes. Nor is it subject to the same experimental vagaries as transformation (Hughes and Caspary, 1970). Thus, while Knowles, Saunders, Currie, Walton, and Field (1970) were able to establish sensitization to peripheral nerve antigen (SNBP) but not central (EF) in Guillain-Barré syndrome, a more recent study with the present method has shown sensitization to both antigens in such cases (Caspary et al., 1971).

If a study of the central and peripheral nervous system in Duchenne dystrophy does establish morphological changes it may be necessary to evaluate the relationship of the dystrophies with KugelbergWelander syndrome. All might then be accommodated within a spectrum of neuromuscular disorder with emphasis varying on different pathological features.

\section{REFERENCES}

Campbell, M. J., McComas, A. J., and Sica, R. E. P. (1970). An electrophysiological study of dystrophia myotonica. $J$. Physiol. (Lond.), 209, 28p-29p.

Caspary, E. A., Currie, S., Walton, J. N., and Field, E. J. (1971). Lymphocyte sensitization to nervous tissues and muscle in patients with the Guillain-Barré syndrome. $J$. Neurol. Neurosurg. Psychiat., 34, 179-181.

Caspary, E. A., and Field, E. J. (1965). An encephalitogenic protein of human origin: some chemical and biological properties. Ann. N.Y. Acad. Sci., 122, 182-198.

Field, E. J., and Caspary, E. A. (1971). Demonstration of sensitized lymphocytes in blood. J. clin. Path., 24, 179181.

Field, E. J., Caspary, E. A., Hall, R., and Clark, F. (1970). Circulating sensitized lymphocytes in Graves' disease: observations on its pathogenesis. Lancet, 1, 1144-1148.

Hughes, D., and Caspary, E. A. (1970). Lymphocyte transformation in vitro measured by tritiated thymidine uptake. I. Lymphocyte culture techniques Int. Arch. Allergy, 37, 506-531.

Knowles, M., and Hughes, D. (1970). A technique for rapid isolation of macrophages from guinea pig peritoneal exudates. J. clin. Path., 23, 824-825. 
Knowles, M., Saunders., M., Currie, S., Walton, J. N., and Field, E. J. (1969). Lymphocyte transformation in the Guillain-Barré syndrome. Lancet, 2, 1168-1170.

McComas, A. J., and Sica, R. E. P. (1970). Muscular dys- trophy: myopathy or neuropathy? Lancet, 1, 1119.

McComas, A. J., Sica, R. E. P., and Currie, S. (1970). Muscular dystrophy: Evidence for a neural factor. Nature (Lond.), 226, 1263-1264. 